\title{
EXTENDING THE THEORY OF PLANNED BEHAVIOUR USING BEHAVIOURAL ECONOMICS TO REDUCE AND ACCESS SMALL WEEE ANTHROPOGENIC STOCKS
}

\author{
Xavier Pierron ${ }^{1, *}$, Ian D. Williams ${ }^{2}$ and Peter J. Shaw ${ }^{2}$ \\ ${ }^{1}$ Edinburgh Napier University Business School, 219 Colinton Rd, Edinburgh EH14 1DJ, United Kingdom \\ 2 International Centre for Environmental Science, Faculty of Engineering and the Environment, University of Southampton, Highfield \\ Campus, Southampton SO17 1BJ, United Kingdom
}

Article Info:

Received:

14 July 2020

Revised:

29 January 2021

Accepted:

4 February 2021

Available online:

31 March 2021

Keywords:

TPB extension

Behavioural economics

Small WEEE

Anthropogenic stocks

Urban mining

\begin{abstract}
From an urban mining perspective stockpiles of Waste of Electronic and Electrical Equipment (WEEE) by individuals represent anthropogenic stocks that could be exploited for precious and critical resources. The current challenge resides in minimising these stocks generation, as well as accessing the resources they represent. Behavioural models such as the Theory of Planned Behaviour (TPB) have been used in waste and resources management studies to understand WEEE end-of-use intentions and behaviours. But the results have been uneven and the very presence of these anthropogenic stocks is the acknowledgement that these models need to be adapted. Based on a review from the waste and resources management literature we found that TPB models incorporating emotions tended to have higher variance explained for intention, but the intention-behaviour gap remained strong. To explain this gap for small WEEE we propose using variables associating emotions with decision-making biases and tendencies that affect individual behaviours. This study is a theoretical elaboration supporting future empirical testing. A TPB extended with behavioural economics could better model small WEEE end-of-use decisions. Improved understanding of small WEEE urban mines generation could, in turn, inform policy and incentives design to transform these anthropogenic stocks into flows of resources within a circular economy.
\end{abstract}

\section{INTRODUCTION AND BACKGROUND}

Household stockpiles of unwanted or disused electronics constitute urban mines that could be exploited. The difficulty resides in accessing these stocks, in effect convincing consumers to part from their unused electronic items. To enhance access to these stocks, we should better understand why these stocks were constituted in the first place. We chose to use small electronics such as mobile and smart phones as a case study since they are ubiquitous and their small size invites for convenient storage, even if not broken. Some waste and resource management studies use behavioural models to measure variance explained for intention and behaviour, with uneven successes. Even fewer studies focus on small electronics stockpiling behaviour. Behavioural models trying to evaluate mobile and smart phones stockpiling behaviour could use variables that are specifically associated with small electronics. How consumers have used their device could influence why they are stockpiling it, especially if the device is still in working order.

\subsection{WEEE situation and issues}

In 2019 alone, close to 54 million tonnes of e-waste across all categories were generated globally (ISWA, 2020). Close to two billion mobile and smart phones were shipped globally in 2019, of which smart 'phone shipments comprised the majority (>75\%; Gartner, 2020). Electronic handsets are now globally ubiquitous and individuals' ownership is high. In 2010, an estimated 3.7 million mobile handsets were stockpiled by students in the UK alone (Ongondo \& Williams 2011). Silveira and Chang (2010) evaluated that between 50 and 90 million devices were stockpiled worldwide. The Ellen MacArthur Foundation (2013) estimated that only $10-15 \%$ of mobile and smart phones are recycled. Accurate figures are difficult to obtain, but the most optimistic estimate is that $20 \%$ are recycled in the UK (Green Alliance, 2015). These low recycling figures could be due to the device working status. Why destroying an item, albeit safely, its utility is higher if untransformed. Waste Electrical and Electronic Equipment (WEEE) regulation addresses waste but in most cases when EEE is replaced 
it is unwanted and still working, especially for small items. Hence most people do not likely recognise it as "waste" per se (Ongondo and Williams, 2011), despite being formally recognised as waste (EU Directive 851,2018 ). In this paper, we will refer to (W)EEE instead of WEEE to underline the uncertainty regarding the status of some electrical and electronic equipment. An unwanted device in working order might not trigger the same end-of-use decision compared to a broken device.

Four key global issues make (W)EEE a priority waste stream: global quantities of (W)EEE; environmental and health impacts; potential and ethical concerns; resource impacts (Ongondo and Williams, 2011). Legislative drivers have provided the impetus for EU Member States to progress from approximately $2.5 \mathrm{~kg}$ of (W)EEE collected per year per capita in 2005 to more than $7.6 \mathrm{~kg}$ in 2016 (Figure 1). A "glass-ceiling" seems to have been reached as the amount of WEEE collected yearly tends to stagnate (Figure 1 ), despite the growth of EEE placed on the market (UNEP, 2019).

\section{2 (W)EEE anthropogenic stocks, urban mining, the circular economy and sustainability}

To break this "glass-ceiling" new approaches could be explored, notably how improving access to these stocks would enhance urban mining initiatives, therefore increase (W)EEE collection rates.

(W)EEE Distinct Urban Mines (DUM) (Ongondo et al., 2015) represent stocks of critical and precious materials. These anthropogenic sources can be characterised according to their availability, approachability and accessibility (Mueller et al., 2017). Urban mining is the process of reclaiming compounds and elements from any kind of anthropogenic stocks (Cossu and Williams, 2015). It can be associated with closed-loop supply chain management, specifically for (W)EEE management and material classification (Vence and Pereira, 2019). It is a useful construct that facilitates an assessment of secondary materials stocks within an urban environment since it delimits an area in which the type/amount of materials accessible at a fixed point in time can be recorded. Cities represent urban mines for secondary materials and efforts should be made to transform these stocks into flows for a circular economy (Kuong et al., 2019).

Recent studies have shown that urban areas are extremely plausible as DUMs. Wilkinson and Williams (2019) reported the ownership, use and hoarding levels of home entertainment EEE in a typical city DUM, highlighting that hoarding is common, especially for smaller or older equipment, due to the perceived residual value. For a specific UK university DUM rich in EEE category 3 (IT and telecommunication equipment), as much as 107 tonnes of secondary materials could be exploitable within a 4-year cycle (Ongondo et al., 2015). Given the 3 to 4 years typically taken to complete a degree, the annual replenishment rate is likely $25 \%$ to $33 \%$ (Ongondo and Williams, 2011). Pierron et al. (2017) estimated that 189 tonnes of ferrous and nonferrous materials from (W)EEE Category 2 could be exploitable within a university campus DUM.

There is clear economic potential for developing urban mines from household stockpiled small (W)EEE (Pierron et al., 2017). To be exploitable, a mine (urban or otherwise) needs to be economically viable, located within reach of an existing logistics network and with materials concentration at an optimal level (Zhang and Kleit, 2016). Therefore, a DUM is a viable concept to evaluate the: i) potential to secure secondary resources from within the anthroposphere and ii) possible cost-effective methods that could be imple-

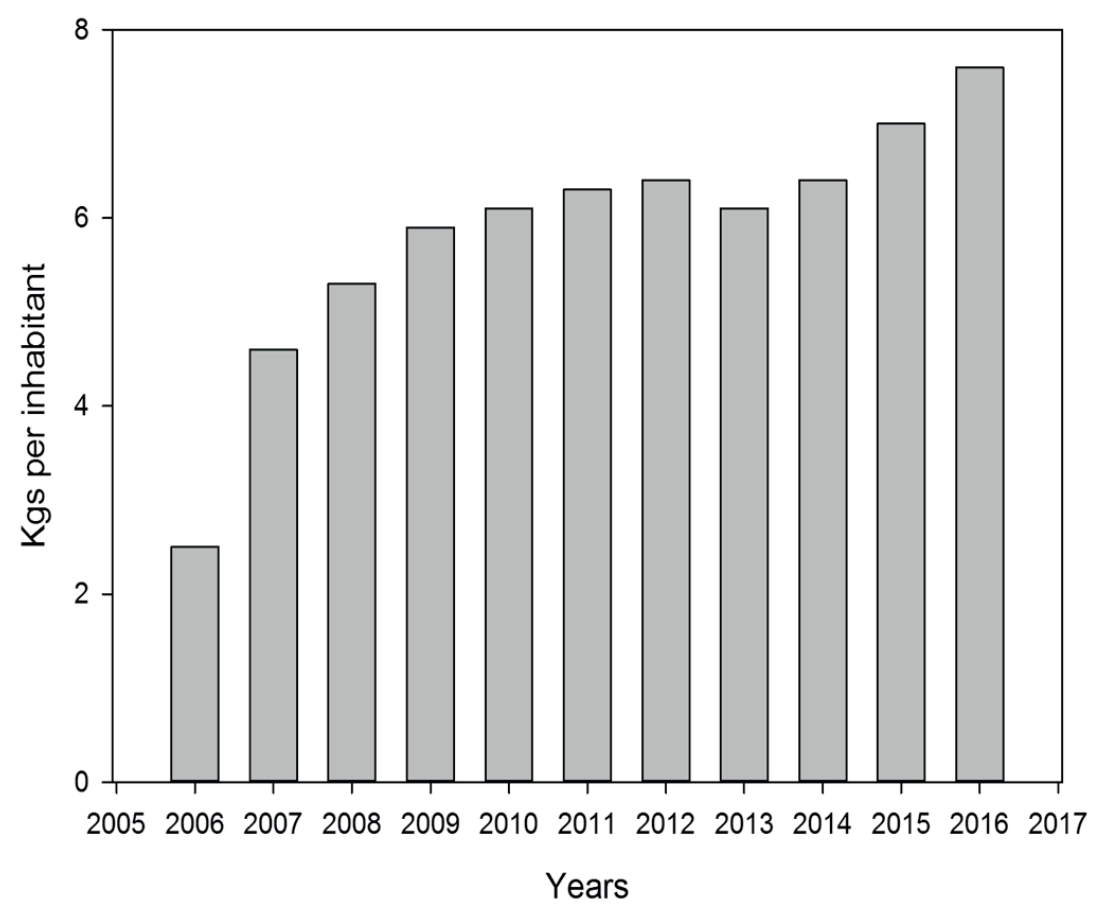

FIGURE 1: EU average (W)EEE collection per inhabitant per year over the period 2006 to 2016 (data sourced from Eurostat, 2019). 
mented to access them. Exploiting anthropogenic stocks within urban mines could participate to gradually shift from a linear to a circular economy.

The circular economy is serving the sustainability agenda with end-of-life management and responsible sourcing. On the other hand, more efforts should be devoted to increasing circular products design and circular business models (Stewart and Niero, 2018). To achieve sustainability, a regenerative system such as advocated by the circular economy principles is required as an initial step. Sustainability is a balanced integration of economic performance, social inclusion, environmental resilience (Geissdoerfer et al., 2017). The circular economy represents environmental, economic and social wins at input and output levels (Korhonen et al., 2018). Accessing anthropogenic stocks is one element of urban mining, therefore creating a loop of materials back into the economy.

To enable urban mining by transforming material stocks into flows, concepts linking anthropogenic stocks to stockpiling behaviour could be investigated further. The legislative framework represents a top-down approach that has resulted in the creation of formal collection systems. However, most of the stock is in "hibernation" (i.e. storage) within households (Wilson et al., 2017). Bottom-up efforts to alter individuals' behaviour are necessary to feed (W) EEE into existing collection systems and reinject products and materials into the economy.

This review of TPB models associated with waste and resources management studies is the basis of a theoretical adaptation offered for future empirical testing. Factors included in WEEE end-use-decisions modelling usually stem from household recycling behaviour and might not be fully adapted, notably for small WEEE such as mobile and smart phones. TPB studies on small WEEE could be extended with factors that are more closely associated with small WEEE characteristics and their influence on users' end-ofuse decisions.

\section{LITERATURE REVIEW AND THEORETICAL STANCE}

\subsection{Introduction}

Modelling the variables influencing small electronics stockpiling behaviour could enable access to precious and critical materials, as well as reducing environmental harm when WEEE is not safely disposed of. Initiatives to change behaviour are routinely informed by and relate to explana- tory models. The Theory of Planned Behaviour (TPB) is a widely-used model for predicting human social behaviour in health-care, psychology, decision analysis and consumer behaviour (Ajzen, 2011) as well as waste and resources management (Chan and Bishop, 2013; Davies et al., 2002; de Leeuw et al., 2015; Joseph R. Hopper and Joyce McCarl Nielsen, 1991; Ojedokun, 2011; Pakpour et al., 2014; Richetin et al., 2010; Wan et al., 2014).

\subsection{Waste and resources management behaviour theory and intrinsic motivators}

Behavioural models have gradually built on the successes and limits set by previous models. Fishbein and Ajzen (1975) and Ajzen (1985) developed models based on psychological principles: Theory of Reasoned Action (TRA) and Theory of Planned Behaviour respectively, were both based on intrinsic motivators such as beliefs, attitudes, intentions, social norms and awareness of consequences. Recent developments have indicated that models associated with emotions, feelings and desires reached higher levels of statistically explained variance than models using TPB and environmental factors. An overview of different models used in waste management and environmental behaviour is provided (Table 1). Most studies use TPB factors as the core and explore other variables of interest (Table 1). Psychological understanding is associated with consumer behaviour and has been used to predict recycling behaviour. Fishbein and Ajzen (1975) proposed the Theory of Reasoned Action (TRA) using beliefs, attitudes and intentions to predict human behaviour (Figure 2). This framework associates attitudes towards the act with subjective norms to determine behavioural intentions, which subsequently influence behaviour.

Although the TRA has proved a reliable model to assess intentions, there was a significant gap between variance explained for intention and behaviour (Carrus et al., 2008; Ajzen,1985). To reduce this gap, Ajzen (1985) extended the TRA by adding perceived behavioural control (PBC) to attitude and subjective norms, resulting in the Theory of Planned Behaviour (Figure 3). PBC is the perception of the ease or difficulty of the specific behaviour, which mitigates or enhances the perception towards an intended behaviour and the social pressure to execute (or not) an identified behaviour (Ajzen, 2011). Individuals assess potential actions against their consequences and perceived value; the decision-making process is influenced by the "acquisition, evaluation, execution and interruption of abstract actions"

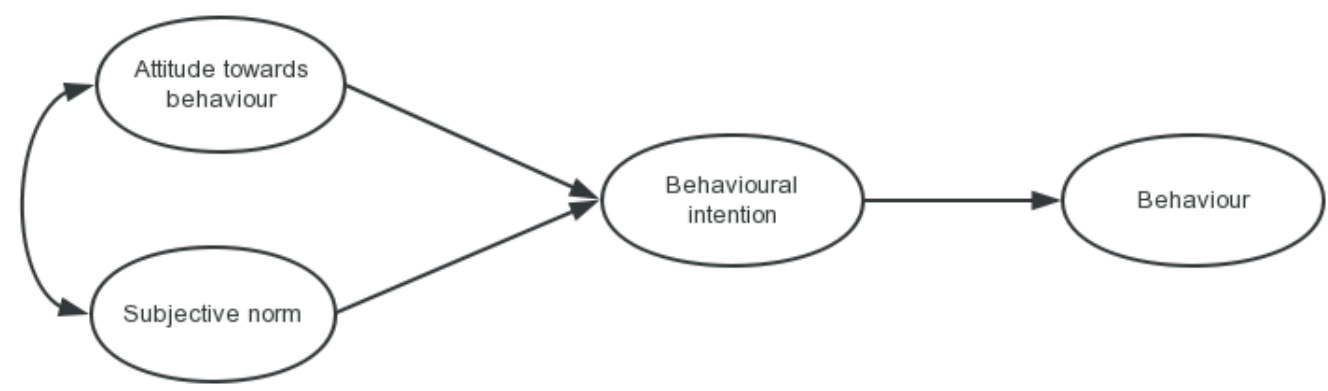

FIGURE 2: Theory of Reasoned Action and factors influencing intentions (Redrawn after Fishbein and Ajzen, 1975). 


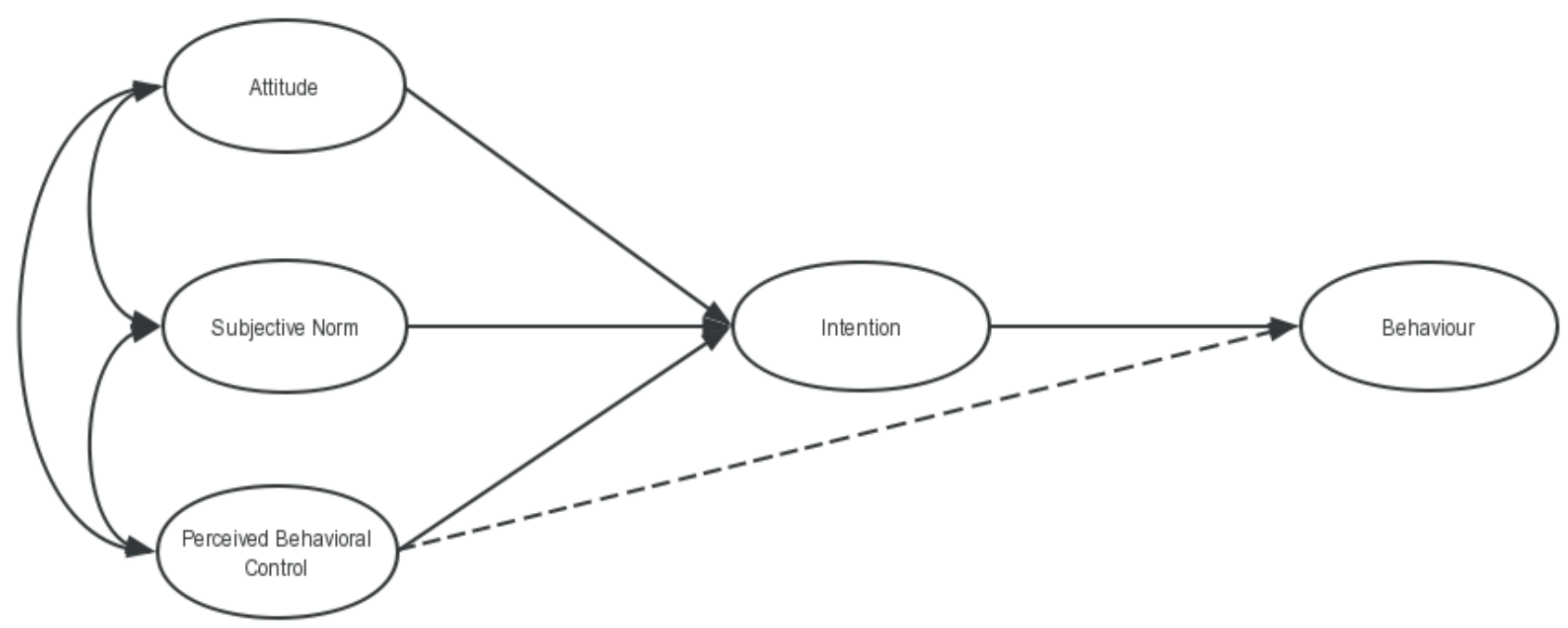

FIGURE 3: The Theory of Planned Behaviour and factors that influence intentions and behaviour (Redrawn after Ajzen, 1985). Solid lines represent a more consistent influence than dotted lines.

(Balleine et al., 2015:2). However, behaviour is difficult to predict accurately and is an unsteady process (Bouton, 2014). Individuals tend to follow behavioural patterns but they can change their behaviours for multiple reasons. Anticipating accurately individuals' actions is thus science and art, ascription of responsibility, personal norms, past behaviour and values.

Despite the widespread use of the TPB, the variance explained for intention and behaviour generally remains low, at $39 \%$ and $27 \%$ respectively (Armitage and Conner, 2001). Therefore, researchers tend to add variables to the TPB framework in an attempt to increase the variance explained. Perugini and Bagozzi (2001) derived a new model based on TPB and emotions, the model of goal-directed behaviour (MGB). This model was subsequently adapted by (Carrus et al., 2008), with minor alterations, in a study of household recycling behaviour. The MGB used the TPB as the base model and includes anticipated negative as well as positive emotions, before engaging in a specific activity (Figure 4). Carrus et al. (2008) found that perceived behavioural control, negative anticipated emotions, desires and frequent recycling behaviour were significant predictors of intentions. Their study explained $85 \%$ of intentions but variance for behaviour was not reported (Table 1). Both Perrugini and Baggozi (2001), and Carrus et al. (2008) used self-reported data. Aside from the TPB factors used as a basis among most of the studies, there is not a set of common factors consistently used to increase variance explained or bridge the intention-behaviour gap (Barr and Gilg, 2005).

Barr et al. (2001) examined predictors of behaviour towards recycling and critiqued the TPB model. The complexity of associations between household attitude and environmental behaviour was acknowledged and aggregated into four categories rather than one: environmental values, situational variables (personal situation in a behavioural context such as access to static recycling centres), socio-demographics, and individual knowledge (Barr et al., 2001). Davies et al. (2002) conducted one of the few stud- ies to measure behaviour directly rather than self-reported behaviour; $48 \%$ of the variance was explained using a combination of factors from TPB (Ajzen, 1985) and Altruism (Schwartz, 1968), highlighting the need to investigate how emotions could be further incorporated in to improve predictive power. Davies et al. (2002:10) found the Norm Activation Model from Schwartz (1968) "a more satisfying point for understanding recycling behaviour in affluent industrial societies" than the TRA and TPB.

The model developed by Davies et al. (2002) is linked to social norms but reinforces the link between intentions and behaviours, and in combination with an awareness of consequences and ascription of responsibility. One limitation, however, is that their sample was drawn from an affluent area in the UK, the Cotswolds, that is not broadly representative of the British population. In evaluating the predictive power of TRA, TPB and the altruistic model, Davies et al. (2002) found the altruistic model more reliable (15\%) compared with TPB (9\%) or TRA (3\%). However, $15 \%$ is still insufficient to provide robust predictive factors.

These models are useful to take a "snapshot" of a current behaviour for specific intrinsic motivators. The TPB forms a robust basis and models including factors associated with emotions tend to have higher variance explained for intention (Table 1), although the explained variance for behaviour is inconsistent. Additionally, studies focus more on intention than actual behaviour. The TPB has been useful to a certain point (Armittage and Conner, 2001). Studies tend to extend the TPB with various factors with mixed results; and there is no set of consistent factors, especially for e-waste. Now the next step is to use behavioural economics and identify which elements could be used to extend the TPB for e-waste.

\subsection{Emotions and decision-making biases}

Behavioural scientists have long investigated the effects of emotions and perceptions on judgment. Tversky and Kahneman (1991) associated the concept of "utility" with ownership, and demonstrated that owning a product 


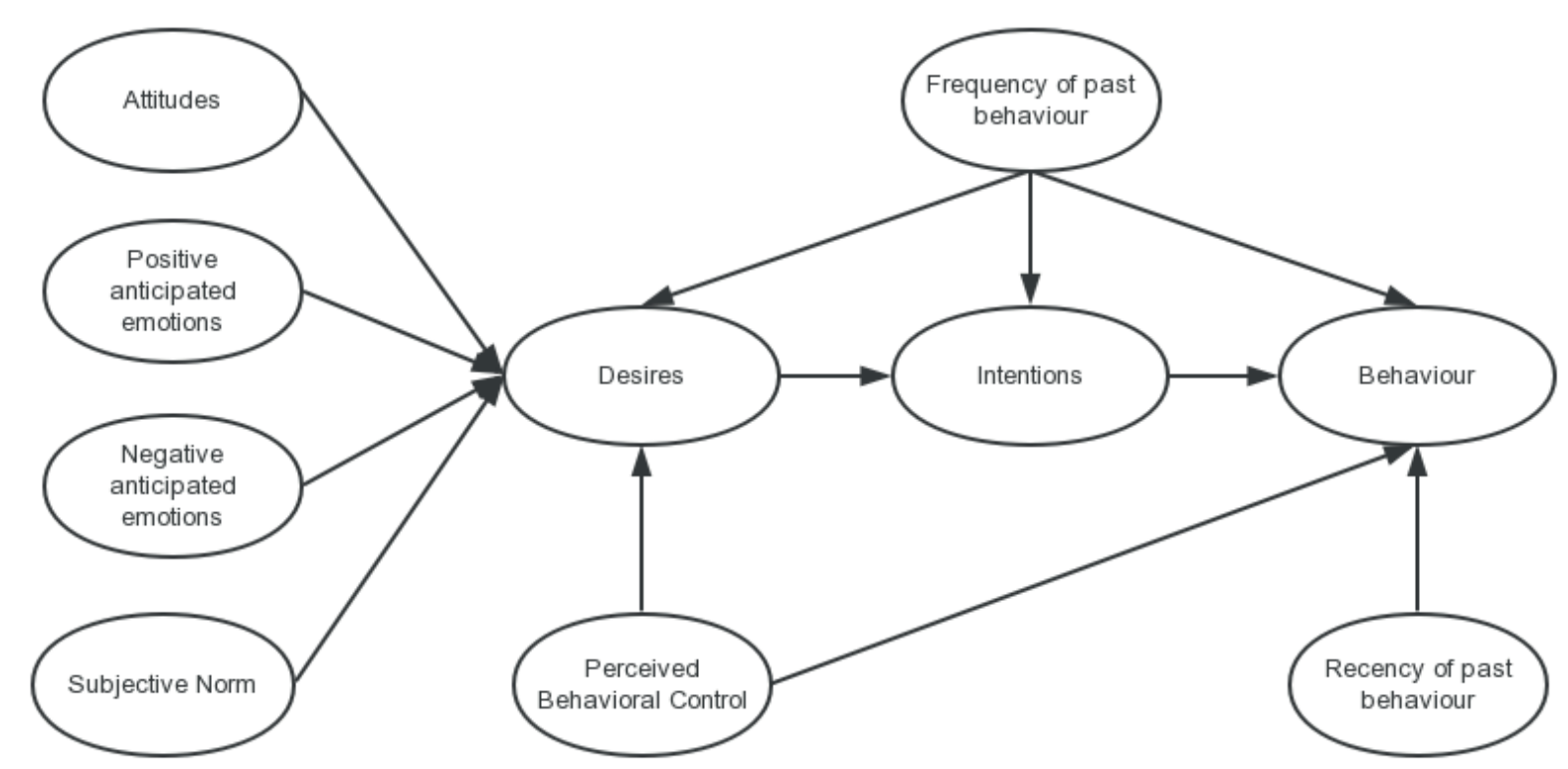

FIGURE 4: The Model of Goal-directed Behaviour (Redrawn after: Perugini and Bagozzi, 2001).

distorts market valuations: if one possesses a product, one will tend to overvalue its price, compared with its actual market value.

Therefore, whilst behavioural models derived from psychology can be applied to understand householders' recycling behaviour, techniques from behavioural economics could be adapted to change behaviour regarding urban mining. Behavioural economics has integrated the heart of its theoretical approach decision-making biases and how to nudge individuals towards desired outcomes. In other words, how emotions and beliefs, such as risk aversion, influence decisions. And how in turn behaviours can be influenced. Adding behavioural economics to TPB models is a logical step taken in the direction set by studies that have included emotions in their modelling.

For example for small electronic devices, given that there are millions of units sitting in people's households (Davies, 2002; Ongondo and Williams, 2011; Wilkinson and Williams, 2019), mobile and smart phone end-of-use barriers could be better understood, reduced and prevented by using the concepts associated with behavioural economics. The works of Kahneman et al. (1991) - on users' endowment effect - and Thaler et al. (2008) - on choice architecture - could also be integrated to the TPB and applied to model altered behaviour.

\subsection{Behavioural economics: The endowment effect}

The endowment effect is the overvaluation of owned objects compared with an object's actual market valuation (Thaler, 1980). "People typically demand more to relinquish the goods they own than they would be willing to pay to acquire these goods" (Morewedge et al., 2009:947). The effect is influenced by factors such as "status quo bias" (Samuelson and Zeckhauser, 1988) and "loss aversion" (Kahneman and Tversky, 1983) experienced by owners when they foresee parting from a possession. Status quo bias is illustrated when an owner takes a decision leading to non-action i.e. an individual tends to remain in a known situation rather than deciding with an uncertain outcome as "the disadvantages of leaving it loom larger than advantages" (Tversky and Kahneman, 1991:198). Loss aversion is the anticipation of a potential future loss. When one foresees parting with an owned object, one projects the situation without the object and associates emotions. If these emotions are negative due to missing the object, one is averse to these negative emotions and is consequently unfavourable to the loss of the object. Losses equivalent to gains are perceived as more painful than the potential positive emotion associated with a symmetrical gain (Kahneman and Tversky, 1983). For example, a loss of $\$ 100$ represents more negative emotion than the positive sensation for a \$100 gain. The endowment effect is associated with the pain felt when an owner contemplates parting from an owned object (Tversky and Kahneman, 1991). To alleviate the potential pain, individuals tend to overvalue an object they own when entering a transaction. According to the endowment effect, someone who has just acquired a brand-new smartphone, if asked to part from it immediately, would ask for more than the device market value. This price increase would be justified to overcome the loss of ownership of an object that has been hitherto desired and the time spent to acquire it.

In addition to loss aversion and status quo bias, other factors have an influence on the endowment effect, such as time and emotional affect. The endowment effect has been demonstrated as immediate by Kahneman et al. (1990). Individuals may experience loss aversion a few moments after acquiring a new object and hence tend to prefer the status quo rather than trading their item. Strahilevitz and Loewenstein (1998) demonstrated that, the longer the duration of ownership of an object, the stronger the endowment effect. These phenomena have been termed the "duration-of-current-ownership effect" and the "duration-of-prior-ownership" effect (Strahilevitz and Loewenstein, 1998:285). The first effect refers to the associa- 
tion of time and ownership. The second effect refers to lost property; the longer it was owned, the more emotionally painful the loss. The influence of time may be explained by the sentimental attachment one might have for an object (Kahneman et al., 1990). On the other hand, strong negative emotions have opposite influences on the endowment effect; Lerner et al. (2004) have shown that disgust actually cancels the effect and that sadness can reverse it.

Other research on the endowment effect has demonstrated some limitations to the concept. Morewedge et al. (2009) disagree with the proposition that loss aversion creates the endowment effect and argue that ownership is a better predictor. Professionals who were employed in trading goods (such as brokers) did not express the endowment effect, as opposed to owners who acquire an object for personal purposes (Morewedge et al. 2009). Dommer and Swaminathan (2013) suggested that the positive feelings associated with possessing an object are more relevant than the negative emotion associated with parting from it. Nevertheless, all studies within this realm acknowledge factors influencing individuals' perception of monetary valuations.

\subsection{Behavioural economics: Choice architecture}

Thaler et al. (2008) developed the concept of "choice architecture" that connects with the notion of routines to complete sets of tasks, such as eating habits, work habits, or end-of-use habits. They argue that if individuals were perfectly rational, they would set their default routines to achieve anticipated outcomes, such as engaging in a healthy lifestyle or saving regularly for the future. Thaler et al. (2008) also demonstrate that habits and routines overcome these rational outcomes. To help individuals making the "right" decisions, they suggest the design of specific alternatives set as default options. Users would then use these default options and start creating new routines. Adapting choice architecture theory to end-of-use decisions for small EEE could improve end-of-use decision-making by creating default options that would prevent stockpiling and disposing of.

Lyengar and Lepper (2000) have postulated that too many choices for common decisions are not helpful to everyday decision-makers; too many alternatives may be confusing and require too much cognitive effort for simple recurring decisions. Tversky and Kahneman (1974) argued that humans use heuristics to approximate complex situations and make rapid decisions. Decision-makers tend to evaluate alternatives based on their past experiences, emotions, state-of-mind and other affective biases. Thaler (1980) claimed that choices should be designed as per expected outcomes for the benefit of the decision-maker. Thaler et al. (2014:429) described a choice architect as the person "who has the responsibility to organise the context in which people make decisions." Thaler et al. (2008) agree with Tversky and Kahneman (1974) in that humans tend to make decisions based on emotions and previous experiences rather than acting as purely rational decision-makers with abilities to rationalise all decisions made constantly. Choice architects can be compared with designers, who reflect on the purpose of objects and design them as per their intended use. A good design should intuitively lead a layperson to make good use of an object without having to be inducted. For example, products made by the company Apple are known for the quality of their hardware and software designs and the relationship the company can create with its users through its products (The Economist, 2016). Choice architects act similarly by focusing on intangible decisions by associating default options (Thaler et al., 2014). Among several alternatives, choices are influenced by creating default options for the most desired outcome.

Thaler et al. (2014) recommended using choice architecture to help consumers to make better decisions for themselves without necessarily noticing that this decision was framed externally. Choice architecture aims to set defaults as per the intended aims. Consumers can optout but Thaler et al. (2008) showed that consumers rarely move away from the default option. They give examples such as in health-care or retirement saving plans where the default option is set to select the best value for healthcare coverage or optimise the amount saved regularly for future retirement. To go further than defaults and to engage consumers on a decision path, Thaler et al. (2008) suggest "nudging" consumers. Nudging can be associated with orienting consumers to their decision-making process towards a favoured outcome, as suggested in the healthcare example above. To create defaults options and nudge consumers, Thaler and Sunstein (2008) have used the NUDGES acronym to structure the approach one should have when designing choice architecture: iNcentives, Understand mappings, use Defaults, Give feedback, Expert error and Structure complex choices into manageable sub-choices (NUDGES).

Johnson et al. (2012:489) draw upon the work of Thaler et al. (2008) to propose 11 tools for choice architecture: reduce the number of alternatives, use technology for decision aids, use defaults, focus on satisfying, create limited time windows, set the decision process in stages, partition options, limit the number of attributes, translate information for better "evaluability", customise information as per the decision-maker profile, and focus on experience.

These recommendations, outlined by Thaler et al. (2008) and Johnson et al. (2012:489), are not inflexible and can be adapted to different situations. Gigerenzer (2002) expressed the idea of a modular toolbox, wherein the choice architect can take any technique that might be suitable to achieve a desired outcome.

Choice architecture is also referred to as libertarian paternalism by Thaler and Sunstein (2003). This apparent contradiction is justified by the decisions set by policy (paternalism) but decision-makers remain free to opt-out (libertarian). This has been described as: "an approach that preserves freedom of choice but that authorises both private and public institutions to steer people in directions that will promote their welfare" (Thaler and Sustein, 2003:179). Mitchell (2005) recognises the power of defaults but argues that this approach is benevolent; this study notes that there is a concern that central planners could have too much power influencing individuals, and defaults would not be set in favour of individuals but rather in the interests of policy-makers. Smith et al. (2013:159) question the eth- 
ical implications of "choice without awareness". Instead of placing the decision-maker in a passive decision-making framework, they recommend the use of "smart defaults" to make "active choices". Smart defaults comprise the proposition of options in real-time according to consumer preferences. These live updates are suitable for online settings. For example, when consumers are shopping online, they select a set of criteria and a series of products / options are presented. Smith et al. (2013) show evidence that smart defaults are now a staple of online shopping experiences, suggesting that they should become the norm when consumers make more important decisions for their future, for example in terms of health care and pensions, especially as these decisions can now be made online with access to large amounts of information.

In 2010 in the UK, choice architecture gained public attention when the British government set the Behavioural Insights Team (BIT, 2010). The BIT aimed to reduce policy production by offering nudges through partnerships with various public bodies such as the Department of Health (to increase organ donation by testing message framing) or HM Treasury (to reduce poverty by setting a decision-making framework aimed at enhancing household economic decisions). As behavioural economics and choice architecture become more widely accepted by public bodies and organisations, examples have also been found in the field of waste/resource management. Baxter and Gram-Hanssen (2016:100) have applied NUDGES to environmental messaging. They argue that messages aimed at promoting mobile 'phone recycling should move away from promoting benefits, as this has limited impact on consumer decisions, but rather focus on focus on the detrimental effects of "do nothing" and the negative environmental consequences. This approach connects with the creation of guilt and negative emotions, which is supposed to trigger an intended behaviour. This may be an over-simplification and may only explore a subset of the "adaptive toolbox" formulated by Gigerenzer (2002). Meder et al. (2018) argue that NUDGES are even more effective when the wider environment is taken into account, rather than solely in the decision-maker's immediate sphere.

The choice architecture approach not yet been applied to urban mining (Pierron et al., 2017). Current end-of-use decisions about small EEE have not yet been framed within a choice architecture intention. (W)EEE collection solutions offered to users are presently unsatisfactory and users would rather stockpile or discard unwanted EEE (Ongondo and Williams, 2011). Individuals choose to hold on to their electronic devices if there is no valid alternative available, despite the legislation in place and the take-back schemes offered by retailers. If the device has some monetary value remaining and the market valuation of the device meets households' expectations, then the device is likely to be sold (Ongondo and Williams, 2011). If this is not the case, it will probably be stockpiled. It seems thus clear that stockpiling behaviour is not a rational economic decision as a household's utility for the devices will continue to decrease over time, and the longer the (W)EEE is stockpiled the more likely it is destined for general refuse (Gutiérrez et al., 2010).
A choice architecture toolbox for small high-end electronics could be implemented to change end-of-use behaviour and support urban mining development (Gigerenzer, 2002). For example, it may be possible to counter the trend of stockpiling mobile electronic devices by offering better end-of-use alternatives to consumers when reaching this decision point. Barr et al. (2013:68) outline that NUDGES and social marketing are effective methods to promote recycling. However, these methods need to be combined with efforts to promote reuse and repair, as end-of-use decision formulations are made in a complex decision-making environment involving many possible alternatives. Consequently, NUDGES and other choice architecture techniques should be adapted simultaneously to the entire palette of end-of-use decisions: reusing, reselling, recycling and discarding.

\subsection{Research Gap and Study Aim}

The literature has showed that the TPB is a useful construct to model end-of-use behaviour in waste and resources management studies. TPB studies integrating emotions in the decision-making process, tend to have a higher variance explained for intention but more rarely for behaviour. But there is no set of factors for small (W)EEE that consistently support a higher variance explained for intention, let alone behaviour when reported.

This study aims at extending the TPB specifically for small (W)EEE end-of-use behaviour, using behavioural economics factors.

To achieve this aim, we have:

- Reviewed TPB models frequently used in waste and resources management studies to establish which core concepts could be used for small (W)EEE stockpiling behaviour evaluation;

- Suggested variables that could explain and reduce the intention-behaviour gap for small (W)EEE.

A dedicated TPB model for small (W)EEE integrating behavioural economics variables could improve modelling end-of-use decisions. Better understanding how anthropogenic stocks are generated could help preventing them as well as accessing these resources within an urban mining environment.

\section{METHODS}

The TPB is one of the most prevalent models in waste management literature to evaluate household recycling behaviour and environmental attitudes. The TRA is rarely used to model waste separation; to our knowledge, only Barata and Castro (2013) have deployed the TRA to investigate waste separation, and among teenagers. The TPB has seldom been used for (W)EEE behavioural modelling with significant results; only Thi Thu Nguyen et al. (2018) have applied the TPB in comparing (W)EEE recycling with household recycling behaviour in general. Therefore, a decision was made to select from a larger pool of research in waste and resource management for this study.

The Science Direct repository was selected for searching as most environmental science journals are referenced 
herein: Resources, Conservation and Recycling, Waste Management, Journal of Cleaner Production, Journal of Environmental Psychology, Journal of Environmental Management, Sustainable Cities and Society. The search terms used were "TPB "or "TRA" and "Waste" or "e-waste" or "(W) EEE". There was no country restriction, the intention being to have as large a pool of publications as possible. Some studies not directly linked to the TPB or TRA were identified as they used a different set of factors but were associated with end-of-use behaviour and yielded high variance explained. They were incorporated in order not to leave out factors that could be associated with end-of-use behaviour (Barr, 2007; Liu et al., 2019; Nduneseokwu et al., 2017).

For each study selected, the factors were listed and the overall variance explained using the Coefficient of Determination $\left(R^{2}\right)$ for intention, and when available for behaviour (Table 2). $R^{2}$ is a statistical measure representing the percentage of variation from one independent variable $(y)$ to variation in a dependent variable $(\mathrm{x})$. For example, if the $R^{2}$ of a model is 0.40 it signifies that $40 \%$ of the observed variation can be explained by the model's input. If $R^{2}=1$, the model and associated factors explain all the variance. There is no consensus on the cut-off value used to determine if a model explains observed variation. However, a cut-off value set at $\mathrm{R}^{2}=0.75$ implies that approximately three-quarters of the variance observed can be explained by the model, which is significant and the associated factors are influential. The investigated studies often used Likert scales to assess self-reported intention and behaviour. To compute $\mathrm{R}^{2}$ some studies used Confirmatory Factor Analysis (CFA) or Structural Equation Modelling (SEM), depending if they were confirming an existing set of factors or exploring new variables and their relationships.

\section{BASIS FOR THEORETICAL ELABORATION ON THE TPB EXTENSION}

This theoretical elaboration rests on studies that have used the TPB in the waste and resources management field. It identified specific studies that have achieved higher variance explained for intention and behaviour. Using their advances in the field, we suggest taking another step in this direction using behavioural economics to improve our understanding of mobile and smart phones end-of-use decisions.

\subsection{Literature Review TPB Data}

Based on the criteria outlined above, 23 suitable previous studies were identified (Table 1). All variables studied are presented, as well as the $\mathrm{R}^{2}$ results for intention, and

TABLE 1: Published studies relating to applications explanatory models of behaviour in the context of waste and resources management. N/A: data not available.

\begin{tabular}{|c|c|c|c|}
\hline \multirow{2}{*}{ Authors } & \multirow{2}{*}{ Topic } & \multicolumn{2}{|c|}{$\mathbf{R}^{2}$} \\
\hline & & Intention & Behaviour \\
\hline 1 - Swami et al. (2011) & Household recycling in the UK & 0.22 & 0.22 \\
\hline 2 - Huffman et al. (2014) & Students' recycling attitudes & 0.23 & 0.08 \\
\hline 3 - Vassanadumrongdee et al. (2018) & Behavioural factors for waste management in Bangkok & 0.25 & N/A \\
\hline 4 - Le et al. (2013) & E-waste recycling in Vietnam & 0.27 & N/A \\
\hline 5 - Knussen et al. (2004) & Household recycling in the UK & 0.29 & N/A \\
\hline 6 - Wan Ab et al. (2012) & Household food waste separation in Malaysia & 0.33 & 0.09 \\
\hline 7 - Tonglet et al. (2004) & Recycling behaviour in the UK & 0.33 & 0.33 \\
\hline 8 - Seacat et al. (2010) & Household recycling & 0.36 & 0.36 \\
\hline 9 - Liu et al. (2019) & Mobile phone recycling behaviour in China & 0.39 & N/A \\
\hline 10 - Manetti et al. (2004) & Recycling behaviour in Italy & 0.39 & N/A \\
\hline 11 - Chan (1998) & Household recycling in Hong Kong & 0.44 & N/A \\
\hline 12 - Pakpour et al. (2014) & Household waste behaviour in Iran & 0.47 & N/A \\
\hline 13 - Kals et al. (1999) & Emotional affinity towards nature & 0.47 & N/A \\
\hline 14 - Davies et al. (2002) & Recycling behaviour in the UK & 0.48 & 0.48 \\
\hline 15 - Bortoleto et al. (2012) & Household waste prevention in the UK & 0.59 & 0.59 \\
\hline 16 - Nduneseokwu et al., (2017) & Formal e-waste collection in Nigeria & 0.62 & N/A \\
\hline 17 - de Leeuw et al. (2015) & High-school students' pro-environmental behaviour & 0.68 & 0.27 \\
\hline 18 - Barr and Gilg (2005) & Household recycling in the UK & 0.68 & 0.46 \\
\hline 19 - Barr (2007) & Household waste management in the UK & 0.7 & 0.83 \\
\hline 20 - Perugini \& Bagozzi, (2001) & Bodyweight regulation in Italy & 0.76 & 0.3 \\
\hline 21 - Carrus et al. (2008) & Household recycling in Italy & 0.82 & N/A \\
\hline 22 - Wan et al. (2014) & Household recycling in Hong Kong & 0.84 & 0.88 \\
\hline 23 - Bamberg et al. (2007) & Public transportation in Germany (Dortmund and Frankfurt) & 0.9 & 0.8 \\
\hline
\end{tabular}




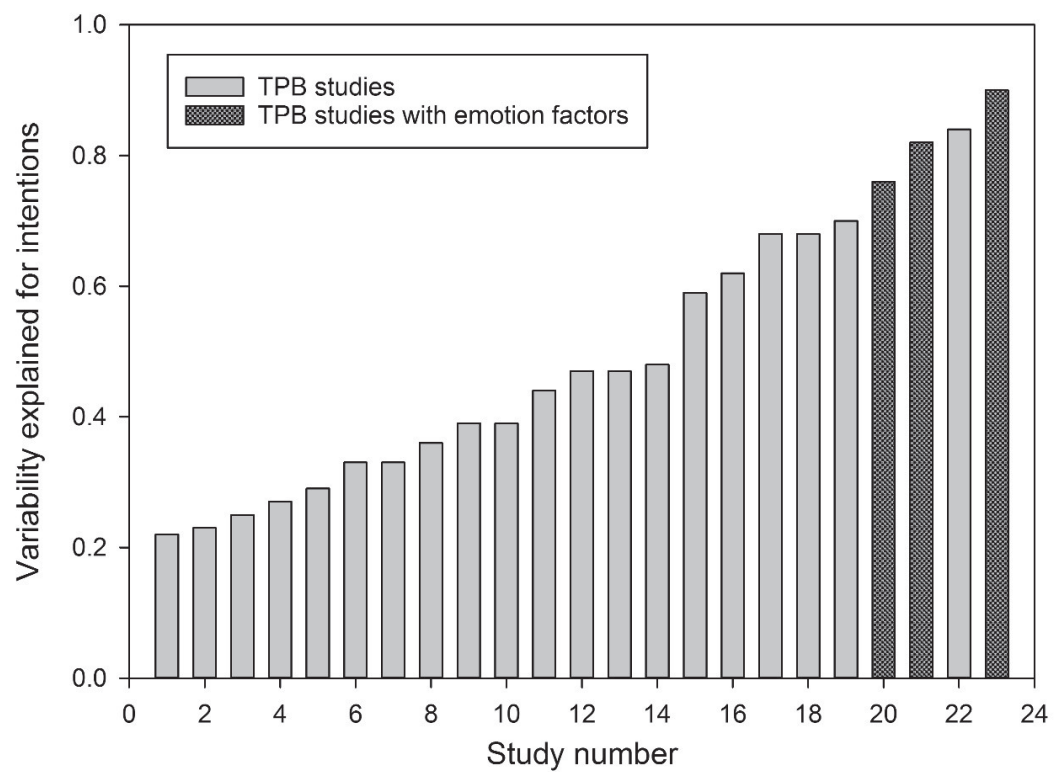

FIGURE 5: Studies ranked in increasing order of variance explained for intention (see Table 1). Studies integrating emotion factors are highlighted.

behaviour when reported. Studies are ranked in increasing order based on $\mathrm{R}^{2}$ for intention.

Usually, variance explained for behaviour is lower than for intentions (Table 2). This observation is partially explained by the difference between declaring a future act and realising this act, i.e. the difference between self-reported behaviour and actual behaviour (e.g. Corral-Verdugo, 1997); and the difference caused by the so-called "value-action gap" (Barr, 2006; Williams and Gunton, 2007).

The study with the lowest variance explained for intention is from Swami et al. (2011) with 22\% (Figure 5); the lowest variance explained for behaviour (8\%) was observed by (Huffman et al., 2014). These studies obtained data from both self-reported questionnaires and observations on students' recycling attitudes in the USA. Three studies focusing on the TPB and (W)EEE were carried out in Vietnam (Le et al., 2013) with $27 \%$ of variance for intention explained, China with $39 \%$ of variance explained (Liu et al. 2019) and Nigeria (Nduneseokwu et al., 2017) with $62 \%$ of intention explained. None of these studies reported variance explained for behaviour, only intention.

In contrast, there are four studies with marked variance explained for intention $\left(R^{2}>0.75\right)$ : 0.76 for Perugini and Bagozzi (2001), 0.82 for Carrus et al. (2008), 0.84 for (Wan et al. (2014) and 0.9 for Bamberg et al. (2007), i.e. two studies relate to household recycling, one to body weight regulation and one to public transportation. In three studies out of four, variables specifically associated with emotions (Perugini and Bagozzi, 2001), feelings (Bamberg et al. (2007), and desires (Carrus et al., 2008) were retained in the models due to their influence on $\mathrm{R}^{2}$ for intentions.

It appears that studies integrating emotions, feelings and desires tend to yield the highest variance explained (Table 1 and Figure 5). These observations suggest that an approach using behavioural economics, which integrates individuals' decision-making biases due to emotions, could be added to the TPB to improve model variance explained for intention and behaviour.

\subsection{Extending the TPB with Behavioural Economics}

Behavioural economics could help explaining the intention-behaviour gap for small (W)EEE. For example, with a smart phone that is still in working order but unused because it has been replaced by a newer version, the owner might still have some utility for the spare device. He might have a higher utility for a backup device than for the monetary incentive reselling the device would generate. There might be a disconnect between what the owner thinks the device is worth and what the device is worth on the secondary market. The Endowment Effect could be used to measure this gap between subjective and objective valuations. Therefore, the strength of the endowment effect could explain stockpiling decisions, thus the generation of anthropogenic stocks when taken on a larger scale. On the other hand, if choice architecture could be adapted to reduce the endowment effect strength, this could prevent the generation of small (W)EEE anthropogenic stocks and facilitating access to existing stocks by enticing individuals' to part from their unused mobile and smart phones.

\subsubsection{Extending with variables associated with emotions to explain the intention-behaviour gap}

As Perugini and Bagoozi (2001) carried out with the MGB (Figure 4), a model based on the TPB with behavioural economics variables could better model small (W)EEE end-of-use behaviour. The TPB has proven to be a robust base (Armitage and Conner, 2001; Ajzen, 2015) to expand from and enhance variance explained for intention and behaviour (Table 1). Behavioural economics variables such as the endowment effect, loss aversion or status quo bias could have certain impacts on stockpiling decisions, therefore on small (W)EEE anthropogenic stock levels. Users 
might find the resale value of their device lower than their expectations. Thus preferring not to engage in this resale activity they might find not worthwhile and keep the device as a spare or backup (endowment effect). Owners might have used their phone for a significant amount of time. Or they might be extremely attached to it as it might have helped them capturing many fond memories. They might feel an emotion such as regret if they parted from their valued and cherished smart phone by reselling it (loss aversion and status quo bias). Hence they might prefer simply keeping it and store it away.

Once these intrinsic factors associated with behavioural economics, such as the endowment effect or loss aversion or status quo bias, are identified for mobile and smart phones end-of-use decisions and behaviour, they could be added to the TPB. This extended TPB would better model and measure small (W)EEE end-of-use behaviour, therefore contributing to close the intention-behaviour gap and informing on the factors influencing the generation of anthropogenic stocks.

\subsubsection{Extending with variables associated with choice archi-} tecture to reduce the intention-behaviour gap

If these end-of-use decisions (or rather the non-behaviour to engage in positive actions to support urban mining) are influenced by the endowment effect, choice architecture could reduce this effect. The endowment effect represents a hindrance that could explain the intention-behaviour gap for small (W)EEE and choice architecture represents a force to counter this effect by using a combination of monetary and non-monetary incentives. The concept of choice architecture to exploit a DUM (Ongondo et al., 2015) already been explored (Pierron et al. 2017) and could be adapted to mobile and smart phones as a case study. As an "adaptive toolbox" (Gigerenzer, 2002), NUDGES can be shaped as per any small (W)EEE specifics (Table 2).

To change behaviour and access anthropogenic stocks, and to render an urban mine exploitable, non-monetary incentives targeted at the endowment effect could be designed using choice architecture (Table 2). Since objective valuations are based on market principles, non-monetary incentives based on users' preferences should be designed to bridge the gap between subjective and objective assessments of value. Enhanced take-back schemes that take into account the endowment effect and users' subjective valuation could offer to give the cash equivalent to a charity, instead of giving back to the user. Strahilevitz and Loewenstein (1998) estimated that charity incentives provide more utility to decision-makers than a cash equivalent. Take-back schemes could provide information on the environmental benefits of reusing a 'phone, instead of manufacturing it e.g. an estimate of the quantity of water saved or the positive impact this action has on carbon reductions. Providing immaterial benefits in addition to monetary rewards could rebalance the misalignment between small (W)EEE second-hand market values and users' perceived values. They would be convenient to implement for takeback schemes and aligned with users' expectations. These incentives should be designed to reduce the barriers set by the EE. NUDGES could represent the framework used to change behaviour for urban mining (Table 2). This framework can and should be adapted (Johnson, 2012:489).

To date, the TPB has been used in few studies dedicated to small (W)EEE end-of-use decision-making (Table 1). However, methods using extrinsic motivators may be applied to alter (W)EEE end-of-use behaviour also need consideration. To be exploitable efficiently, DUMs need end-users to behave in such a fashion that it becomes possible to access stockpiles and transform discarding habits into recycling opportunities and stockpiling into reuse decisions. Behaviour change is a complex process that requires the use of various incentives, intrinsic and/or extrinsic (Schultz et al., 1995).

\subsubsection{TPB extended for small electronics end-of-use deci- sions}

This extended TPB could help explaining the weakness between intention and behaviour for small (W)EEE. Many

TABLE 2: Choice architecture principles applied to nudging mobile and smart phone users to trade-in their hoarded device (Thaler et al., 2008).

\begin{tabular}{|c|c|}
\hline Nudges & Description \\
\hline iNcentives & $\begin{array}{l}\text { Incentive mix (monetary and non-monetary) based on device characteristics and owners' categorical variables } \\
\text { (loss aversion, status quo bias, endowment effect) }\end{array}$ \\
\hline Understanding mappings ${ }^{1}$ & $\begin{array}{l}\text { Small electronics collectors explain stockpiled mobile devices' value declines over time to nudge decision to use } \\
\text { hoarded devices as an additional discount toward the acquisition of a new device }\end{array}$ \\
\hline Defaults & $\begin{array}{l}\text { Default decision for mobile and smart phones tends to be stockpiling. Small electronics collectors to counter this } \\
\text { default and nudge owners to trade-in their stockpiled device within a time period }\end{array}$ \\
\hline Giving feedback & $\begin{array}{l}\text { Giving information to each owner: small electronics collectors deliver information on hoarded device second-hand } \\
\text { value, incentive mix based on device characteristics and owner's categorical variables, information on sustainable } \\
\text { practice (what happens to the phone when collected by small electronics producers with a positive impact on } \\
\text { carbon footprint and reduced resources depletion) }\end{array}$ \\
\hline Expecting errors & $\begin{array}{l}\text { Incentive mix not adapted to user preferences. Small electronics collectors to use data gathered over time and } \\
\text { experience to improve incentive mix }\end{array}$ \\
\hline Structuring complex choices & $\begin{array}{l}\text { Structure decision into logical steps: } \\
\text { Owner to understand that stockpiling has marginal utility as usually devices are not used for their intended purpose } \\
\text { Stockpiled devices' value declines over time so will the incentive mix. Immediate decision has the highest utility for } \\
\text { owner } \\
\text { User is contributing to positive outcome for the environment and the circular economy }\end{array}$ \\
\hline
\end{tabular}

${ }^{1}$ How information presentation influences decisions 
studies (Table 1) have reported only intention and not behaviour. When reported, behaviour is significantly lower than intentions in terms of explained variance (Perugini and Bagozzi, 2001). The willingness to extend the TPB with variables that are not directly associated with attitudes towards the environment is supported by Echegaray and Hansstein (2017). They found that despite respondents having a positive attitude towards the environment, they failed to engage in a (W)EEE recycling behaviour. The most successful TPB studies in waste and resources management had integrated emotions in their set of factors (Table 1). Using variables that take into account emotions and their influence on the decision-making process, such as in behavioural economics, could be worth investigating. Especially for stockpiled small (W)EEE still in working order. Individuals who have kept a spare mobile or smart phone as a back up might not perceive this device as waste. Hence the environmental factors usually associated with TPB studies in waste and resources management might not be relevant. Integrating behavioural economics variables for small (W)EEE could reduce the intention-behaviour gap (Figure 6).

We propose to take the TPB as a proven and robust basis but we acknowledge the intention-behaviour gap remains problematic in most studies. We suggest that the endowment effect is at work between the intention and the actual behaviour to safely dispose of an unwanted device still in working order. Individuals prefer keeping the unwanted device as a spare because they have higher utility for this status quo and might regret their decision at a later stage. This endowment effect could have an influence on small (W)EEE stockpiling decisions. Undersanting the nature of the intention-behaviour gap for mobile and smart phones end-of-use decisions could inform the de- sign of solutions directly targeted at the endowment effect (Table 2). Choice architecture is an adaptable and flexible approach aiming at altering behaviour towards a desired outcome (Thaler et al., 2008). An extended TPB with behavioural economics could be further investigated to limit the generation of small (W)EEE anthropogenic stocks as well as accessing these resources to support the development of urban mining using existing formal collection systems.

\section{CONCLUSIONS AND RECOMMENDATIONS}

Historically, most behavioural models for waste and resources management have been based on variations of the TPB. These models have evolved and improved, but they still need refinement. From this review, we can conclude that behavioural models derived from psychology - such as the TPB - have been applied to understand individuals' recycling behaviour but the variance explained for intention and behaviour-related factors generally remains low. Models that incorporate emotional variables tend to have a higher explained variance for intention. The endowment effect is likely to be a significant barrier to the release of (W) EEE back into the circular economy. To overcome the endowment effect, non-monetary incentives based on users' preferences could be designed to bridge the gap between subjective and objective assessments of the value of (W) EEE. Techniques integrating emotional variables such as behavioural economics and choice architecture could be incorporated into behavioural models such as the TPB to better evaluate small (W)EEE anthropogenic stocks generation and facilitating access to these resources.

This paper uses secondary data as the basis for the analyses and interpretation presented. Future research could test and apply behavioural economics concepts to

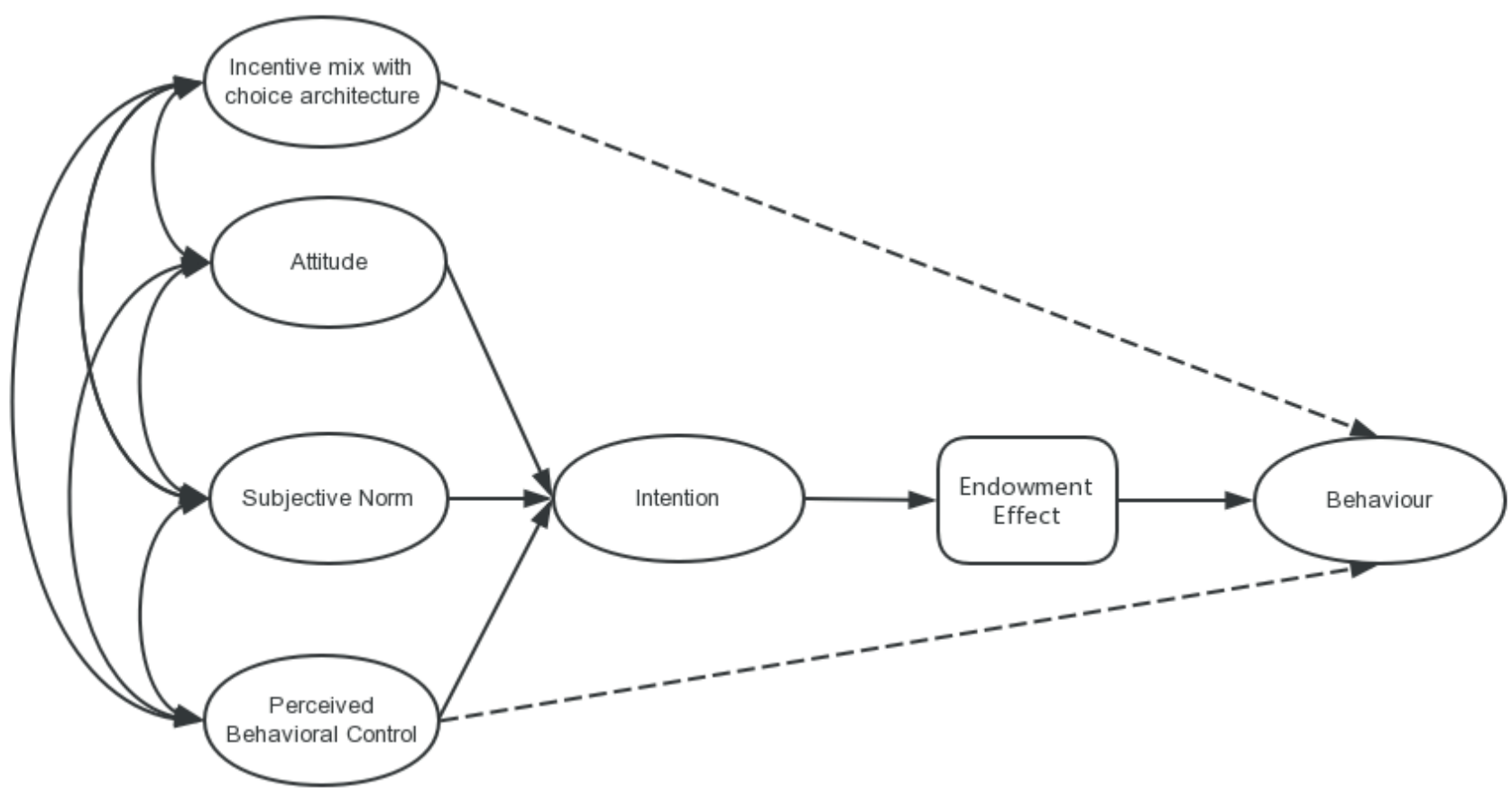

FIGURE 6: TBP extended illustrating the potential influence of the endowment effect on behaviour and choice architecture to counter the endowment effect and alter end-of-use behaviour, based on Tables 1 and 2. 
small (W)EEE using primary qualitative and quantitative data. Most TPB studies report explained intention but fewer explained behaviour. Future research accessing small (W)EEE anthropogenic stocks for urban mining could focus therefore on end-of-use behaviour rather than intention. Furthermore, the behavioural economics theories discussed in this paper could be tested using loss aversion, status quo bias and the endowment effect affecting small (W)EEE end-of-use decisions and behaviour. Based on these findings, incentives could be designed using choice architecture to access small (W)EEE anthropogenic stocks and improve urban mining efforts to reinsert devices and resources into the economy.

\section{REFERENCES}

Ajzen, I. (2011). The theory of planned behaviour: reactions and reflections. Psychology \& health 26, 1113-27. https://doi.org/10.1080/ 08870446.2011.613995

Ajzen, I. (1985). 'From Intentions to Actions: A Theory of Planned Behavior', in: Kuhl, P.D.J., Beckmann, D.J. (Eds.), Action Control, SSSP Springer Series in Social Psychology (pp. 11-39). Springer Berlin Heidelberg. https://doi.org/10.1007/978-3-642-69746-3_2

Ajzen, I., (2015) The theory of planned behaviour is alive and well, and not ready to retire: a commentary on Sniehotta, Presseau, and Araújo-Soares, Health Psychology Review, 9:2, 131137, DOI: 10.1080/17437199.2014.883474

Armitage, C.J., Conner, M. (2001). Efficacy of the Theory of Planned Behaviour: a meta-analytic review. The British journal of social psychology / the British Psychological Society 40, 471-99.

Baldé, C.P., Forti, V., Gray, V., Kuehr, R., Stegmann, P. (2017). Quantities, Flows, and Resources (No. 3), The Global E-waste Monitor. United Nations University, Bonn/Geneva/Vienna.

Balleine, B.W., Dezfouli, A., Ito, M., Doya, K. (2015). Hierarchical control of goal-directed action in the cortical-basal ganglia network. Current Opinion in Behavioral Sciences, Neuroeconomics 5, 1-7. https://doi.org/10.1016/j.cobeha.2015.06.001

Bamberg, S., Hunecke, M., Blöbaum, A. (2007). Social context, personal norms and the use of public transportation: Two field studies. Journal of Environmental Psychology 27, 190-203. https://doi. org/10.1016/j.jenvp.2007.04.001

Barata, R., Castro, P. (2013). "I feel recycling matters... sometimes": The negative influence of ambivalence on waste separation among teenagers. The Social Science Journal 50, 313-320. http://dx.doi. org/10.1016/j.soscij.2013.05.007

Barba-Gutiérrez, Y., Adenso-Díaz, B., Hopp, M. (2008). An analysis of some environmental consequences of European electrical and electronic waste regulation. Resources, Conservation and Recycling 52, 481-495. https://doi.org/10.1016/j.resconrec.2007.06.002

Barr, S. (2007). Factors Influencing Environmental Attitudes and Behaviors A U.K. Case Study of Household Waste Management. Environment and Behavior 39, 435-473. https://doi. org/10.1177/0013916505283421

Barr, S. (2006). Environmental Action in the Home: Investigating the "Value-Action" Gap. Geography 91, 43-54.

Barr, S., Gilg, A.W. (2005). Conceptualising and analysing household attitudes and actions to a growing environmental problem: Development and application of a framework to guide local waste policy. Applied Geography 25, 226-247. https://doi.org/10.1016/j. apgeog.2005.03.007

Barr, S., Gilg, A.W., Ford, N.J. (2001). A conceptual framework for understanding and analysing attitudes towards household-waste management. Environment and Planning A 33, 2025-2048. https://doi. org/10.1068/a33225

Barr, S., Guilbert, S., Metcalfe, A., Riley, M., Robinson, G.M., Tudor, T.L. (2013). Beyond recycling: An integrated approach for understanding municipal waste management. Applied Geography 39, 67-77. https://doi.org/10.1016/j.apgeog.2012.11.006

Baxter, J., Gram-Hanssen, I. (2016). Environmental message framing: Enhancing consumer recycling of mobile phones. Resources, Conservation and Recycling 109, 96-101. https://doi.org/10.1016/j. resconrec.2016.02.012
Binnemans, K., Jones, P.T., Blanpain, B., Van Gerven, T., Yang, Y., Walton, A., Buchert, M. (2013). Recycling of rare earths: a critical review. Journal of Cleaner Production 51, 1-22. https://doi.org/10.1016/j. jclepro.2012.12.037

BIT (2010). About us [WWW Document]. URL https://www.bi.team/ (accessed 10.31.19).

Bouton, M.E. (2014). Why behavior change is difficult to sustain. Preventive Medicine, Behavior Change, Health, and Health Disparities 68, 29-36. https://doi.org/10.1016/j.ypmed.2014.06.010

Carrus, G., Passafaro, P., Bonnes, M. (2008). Emotions, habits and rational choices in ecological behaviours: The case of recycling and use of public transportation. Journal of Environmental Psychology 28, 51-62. https://doi.org/10.1016/j.jenvp.2007.09.003

Chan, L., Bishop, B. (2013). A moral basis for recycling: Extending the theory of planned behaviour. Journal of Environmental Psychology 36, 96-102. https://doi.org/10.1016/j.jenvp.2013.07.010

COM614. (2015). Closing the loop - An EU action plan for the Circular Economy.

Comply Direct (2019). Demanding 2019 WEEE Collection Targets Confirmed [WWW Document]. URL https://www.complydirect.com/ news/demanding-2019-weee-collection-targets-confirmed/ (accessed 10.28.19).

Corral-Verdugo, V. (1997). Dual 'Realities' of Conservation Behavior: Self-Reports vs Obervations of Reuse and Recycling Behavior. Journal of Environmental Psychology 17, 135-145. https://doi. org/10.1006/jevp.1997.0048

Cossu, R., Williams, I.D. (2015). Urban mining: Concepts, terminology, challenges. Waste Management, Urban Mining 45, 1-3. https:// doi.org/10.1016/j.wasman.2015.09.040

Craig Smith, N., G. Goldstein, D., J. Johnson, E. (2013). Choice Without Awareness: Ethical and Policy Implications of Defaults. American Marketing Association 32, 159-172.

Daum, K., Stoler, J., Grant, R., Daum, K., Stoler, J., Grant, R.J. (2017). Toward a More Sustainable Trajectory for E-Waste Policy: A Review of a Decade of E-Waste Research in Accra, Ghana. International Journal of Environmental Research and Public Health 14, 135. https://doi.org/10.3390/ijerph14020135

Davies, J., Foxall, G., Pallister, J. (2002). Beyond the Intention-Behaviour Mythology An Integrated Model of Recycling. Marketing Theory 2, 29-113. https://doi.org/10.1177/1470593102002001645

de Leeuw, A., Valois, P., Ajzen, I., Schmidt, P. (2015). Using the theory of planned behavior to identify key beliefs underlying pro-environmental behavior in high-school students: Implications for educational interventions. Journal of Environmental Psychology 42, 128-138. https://doi.org/10.1016/j.jenvp.2015.03.005

Department for Business Innovation and Skills (2013). Implementation of the WEEE Recast Directive 2012/19/EU and Changes to the UK WEEE System (Business Regulation No. BIS/11/1179), BIS. Department for Business Innovation and Skills, London.

Di Maria, F., Micale, C., Sordi, A., Cirulli, G., Marionni, M. (2013). Urban Mining: Quality and quantity of recyclable and recoverable material mechanically and physically extractable from residual waste. Waste Management 33, 2594-2599. https://doi.org/10.1016/j. wasman.2013.08.008

Directive 125/EC. (2009). Directive 2009/125/EC of the European Parliament and of the Council of 21 October 2009 establishing a framework for the setting of ecodesign requirements for energyrelated products. Text with EEA relevance.

Directive 2002/96/EC (2002). Directive 2002/96/EC of the European Parliament and of the Council of 27 January 2003 on waste electrical and electronic equipment (WEEE). Joint declaration of the European Parliament, the Council and the Commission relating to Article 9, 037.

Directive 2012/19/EU. (2012). Directive 2012/19/EU of the European Parliament and of the Council of 4 July 2012 on waste electrical and electronic equipment (WEEE). Text with EEA relevance, 197.

Dommer, S.L., Swaminathan, V. (2013). Explaining the Endowment Effect through Ownership: The Role of Identity, Gender, and SelfThreat. Journal of Consumer Research 39, 1034-1050.

Echegaray, F., \& Hansstein, F. V. (2017). Assessing the intention-behavior gap in electronic waste recycling: the case of Brazil. Journal of Cleaner Production, 142, 180-190. https://doi.org/10.1016/j. jclepro.2016.05.064

Eliseeva, S.V., Bünzli, J.-C.G. (2011). Rare earths: jewels for functional materials of the future. New Journal of Chemistry 35, 1165. 
Ellen MacArthur Foundation (2013). Economic and business rationale for an accelerated transition (Online No. 1), Towards the Circular Economy. Ellen MacArthur Foundation, Cowes, Isle of Wight.

EU Directive 851, 2018. Directive (EU) 2018 of the European Parliament and of the Council of 30 May 2018 amending Directive 2008/98/ EC on waste.

European Commission, 2017a. Critical Raw Materials List for the EU. European Commission.

European Commission, 2017b. Report on the implementation of the Circular Economy Action Plan (Text No. 1). Brussels.

European Commission, 2014. Report on Critical Raw Materials for the EU (No. 2), Report of the Ad hoc Working Group on defining critical raw materials. European Commission, Brussels.

European Commission, 2010. Critical Raw Materials (No. 1). European Commission.

European Parliament, 2019. Establishment of a framework to facilitate sustainable investment.

Eurostat, 2016. Waste Electrical and Electronic Equipment (WEEE) - Eurostat [WWW Document]. URL http://ec.europa.eu/eurostat/web/ waste/key-waste-streams/weee (accessed 9.3.16).

Fishbein, M., Ajzen, I. (1975). Belief, attitude, intention, and behavior: an introduction to theory and research. Addison-Wesley Pub. Co.

Gartner. (2020). Gartner Says Global Smartphone Sales Declined 2.7\% in First Quarter of 2019 [WWW Document]. Gartner. URL https:// www.gartner.com/en/newsroom/press-releases/2020-06-01gartner-says-global-smartphone-sales-declined-20--in- (accessed 11.24.20).

Geissdoerfer, M., Savaget, P., Bocken, N. M. P., \& Hultink, E. J. (2017). The Circular Economy - A new sustainability paradigm? Journa of Cleaner Production, 143, 757-768. https://doi.org/10.1016/j. jclepro.2016.12.048

Gigerenzer, G. (2002). Bounded Rationality: The Adaptive Toolbox, New Ed edition. ed. MIT Press, Cambridge, Mass.

Green Alliance (2015). A circular economy for smart devices / Opportunities in the US, UK and India, Green Alliance. Green Alliance, London.

Gutiérrez, E., Adenso-Díaz, B., Lozano, S., González-Torre, P. (2010). A competing risks approach for time estimation of household WEEE disposal. Waste Management 30, 1643-1652. https://doi. org/10.1016/j.wasman.2010.02.032

Huffman, A.H., Van Der Werff, B.R., Henning, J.B., Watrous-Rodriguez, K. (2014). When do recycling attitudes predict recycling? An investigation of self-reported versus observed behavior. Journal of Environmental Psychology 38, 262-270. https://doi.org/10.1016/j. jenvp.2014.03.006

Huisman, J. (2013). WEEE recast : from $4 \mathrm{~kg}$ to $65 \%$ : the compliance consequences. United Nations University.

Iswa.org. 2020. ISWA: The Global E-Waste Monitor 2020. [online] Available at: <https://www.iswa.org/home/news/news-detail/article/-21c8325490/109/> [Accessed 25 November 2020].

lyengar, S.S., Lepper, M.R. (2000). When Choice is Demotivating: Can One Desire Too Much of a Good Thing? Journal of Personality and Social Psychology 79, 995-1006.

Jonhson, E.J., G. C. Dellaert, B., Fox, C., G. Goldstein, D., Haubl, G., P. Larrick, R., W. Payne, J., Peters, E., Schkade, D., Wansick, D., U. Weber, E. (2012). Beyond nudges: Tools of a choice architecture. Mark Lett 23, 487-504.

Hopper, J.R., Nielsen, J.M. (1991). Recycling as Altruistic Behavior: Normative and Behavioral Strategies to Expand Participation in a Community Recycling Program. Environment and Behavior 23 195-220. https://doi.org/10.1177/0013916591232004

Kahneman, D., Knetsch, J.L., Thaler, R.H. (1991). Anomalies: The Endowment Effect, Loss Aversion, and Status Quo Bias. The Journal of Economic Perspectives 5, 193-206

Kahneman, D., Knetsch, J.L., Thaler, R.H. (1990). Experimental Tests of the Endowment Effect and the Coase Theorem. Journal of Political Economy 98, 1325-1348.

Kahneman, D., Tversky, A. (1983). Choices, Values, and Frames. American Psychological Association 39, 341-350.

Korhonen, J., Honkasalo, A., \& Seppälä, J. (2018). Circular Economy: The Concept and its Limitations. Ecological Economics, 143, 3746. https://doi.org/10.1016/j.ecolecon.2017.06.041

Krook, J., Baas, L. (2013). Getting serious about mining the technosphere: a review of recent landfill mining and urban mining research. Journal of Cleaner Production, Special Volume: Urban and Landfill Mining 55, 1-9. https://doi.org/10.1016/j.jclepro.2013.04.043
Krook, J., Carlsson, A., Eklund, M., Frändegård, P., Svensson, N., (2011). Urban mining: hibernating copper stocks in local power grids. Journal of Cleaner Production 19, 1052-1056.

Kuong, I. H., Li, J., Zhang, J., \& Zeng, X. (2019). Estimating the Evolution of Urban Mining Resources in Hong Kong, Up to the Year 2050. Environmental Science and Technology, 53(3), 1394-1403. https:// doi.org/10.1021/acs.est.8b04063

Lambeth, Veolia UK. (2017). Waste Electrical and Electronic Equipment (WEEE) recycling event | Lambeth Council [WWW Document]. URL https://www.lambeth.gov.uk/events/waste-electrical-and-electronic-equipment-weee-recycling-event (accessed 10.28.19).

Le Bozec, A. (2008). The implementation of PAYT system under the condition of financial balance in France. Waste Management, Pay as you throw: a tool for urban waste management $28,2786-2792$. https://doi.org/10.1016/j.wasman.2008.03.028

Le, H.-L., Yamasue, E., Okumura, H., Ishihara, K.N. (2013). 'Analysis of Intentions to Recycle Electronic Waste (E-Waste) Using the Theory of Planned Behavior: A Case Study in Urban Areas of Vietnam', Green Energy and Technology (pp. 73-79) Springer Japan

Lerner, J., Small, D., Loewenstein, G. (2004). Heart Strings and Purse Strings. American Psychological Society, Psychological Science $15,337-342$

Let's Recycle. (2019). DEFRA proposes WEEE target hike [WWW Document]. letsrecycle.com. URL https://www.letsrecycle.com/ news/latest-news/defra-proposes-weee-target-hike/ (accessed 10.28.19).

Liu, J., Bai, H., Zhang, Q., Jing, Q., Xu, H. (2019). Why are obsolete mobile phones difficult to recycle in China? Resources, Conservation and Recycling 141, 200-210. https://doi.org/10.1016/j.resconrec.2018.10.030

Meder, B., Fleischhut, N., Osman, M. (2018). Beyond the confines of choice architecture: A critical analysis. Journal of Economic Psychology 68, 36-44. https://doi.org/10.1016/j.joep.2018.08.004

Milovantseva, N., Saphores, J.-D. (2013). Time bomb or hidden treasure? Characteristics of junk TVs and of the US households who store them. Waste Management, Special Thematic Issue: Urban Mining Urban Mining 33, 519-529. https://doi.org/10.1016/j.wasman.2012.07.020

Mitchell, G., 2005. Libertarian Paternalism Is an Oxymoron. Nortwestern University Law Review 99, 1-42.

Morewedge, C.K., Shu, L.L., Gilbert, D.T., Wilson, T.D. (2009). Bad riddance or good rubbish? Ownership and not loss aversion causes the endowment effect. Journal of Experimental Social Psychology 45, 947-951. https://doi.org/10.1016/j.jesp.2009.05.014

Mueller, S.R., Wäger, P.A., Turner, D.A., Shaw, P.J., Williams, I.D. (2017). A framework for evaluating the accessibility of raw materials from end-of-life products and the Earth's crust. Waste Management 68, 534-546. https://doi.org/10.1016/j.wasman.2017.05.043

Nduneseokwu, C., Qu, Y., Appolloni, A., Nduneseokwu, C.K., Qu, Y., Appolloni, A., 2017. Factors Influencing Consumers' Intentions to Participate in a Formal E-Waste Collection System: A Case Study of Onitsha, Nigeria. Sustainability 9, 881. https://doi.org/10.3390/ su9060881

Oguchi, M., Kameya, T., Yagi, S., Urano, K. (2008). Product flow analysis of various consumer durables in Japan. Resources, Conservation and Recycling 52, 463-480. https://doi.org/10.1016/j.resconrec.2007.06.001

Ojedokun, O. (2011). Attitude towards littering as a mediator of the relationship between personality attributes and responsible environmental behavior. Waste Management 31, 2601-2611. https://doi. org/10.1016/j.wasman.2011.08.014

Ongondo, F.O., Williams, I.D. (2011). Greening academia: Use and disposal of mobile phones among university students. Waste Management 31, 1617-1634. https://doi.org/10.1016/j.wasman.2011.01.031

Ongondo, F.O., Williams, I.D., Whitlock, G. (2015). Distinct Urban Mines: Exploiting secondary resources in unique anthropogenic spaces. Waste Management, Urban Mining 45, 4-9. https://doi. org/10.1016/j.wasman.2015.05.026

Oswald, I., Reller, A. (2011). E-Waste : A Story of Trashing , Trading , and Valuable Resources.

Pakpour, A.H., Zeidi, I.M., Emamjomeh, M.M., Asefzadeh, S., Pearson, H. (2014). Household waste behaviours among a community sample in Iran: An application of the theory of planned behaviour. Waste Management, Waste Management on Asia 34, 980-986. https://doi.org/10.1016/j.wasman.2013.10.028 
Perugini, M., Bagozzi, R.P. (2001). The role of desires and anticipated emotions in goal-directed behaviours: Broadening and deepening the theory of planned behaviour. British Journal of Social Psychology 40, 79-98. https://doi.org/10.1348/014466601164704

Pierron, X., Williams, I.D., Shaw, P.J., Cleaver, V. (2017). Using choice architecture to exploit a university Distinct Urban Mine. Waste Management 68, 547-556. https://doi.org/10.1016/j.wasman.2017.06.034

Recycling Today (2018). Rare opportunity to recycle rare earths [WWW Document]. Recycling Today. URL http://www.recyclingtoday.com/ article/rare-earth-metals-recycling/ (accessed 9.6.18).

Richetin, J., Sengupta, A., Perugini, M., Adjali, I., Hurling, R., Greetham, D. Spence, M. (2010). A micro-level simulation for the prediction of intention and behavior. Cognitive Systems Research 11, 181-193. https://doi.org/10.1016/j.cogsys.2009.08.001

Robinson, B.H. (2009). E-waste: an assessment of global production and environmental impacts. The Science of the total environment 408, 183-91. https://doi.org/10.1016/j.scitotenv.2009.09.044

Samuelson, W., Richard, Z. (1988). Status Quo Bias in Decision Making. Journal of Risk and Uncertainty 1, 7-59.

Schultz, P.W., Oskamp, S., Mainieri, T. (1995). Who recycles and when? A review of personal and situational factors. Journal of Environmental Psychology 15, 105-121. https://doi.org/10.1016/02724944(95)90019-5

Schwartz, S.H. (1968). Awareness of Consequences and the Influence of Moral Norms on Interpersonal Behavior. Sociometry 31, 355369. https://doi.org/10.2307/2786399

Silveira, G.T.R., Chang, S.-Y. (2010). Cell phone recycling experiences in the United States and potential recycling options in Brazil. Waste Management, Special Thematic Section: Sanitary Landfilling 30, 2278-2291. https://doi.org/10.1016/j.wasman.2010.05.011

Simoni, M., Kuhn, E.P., Morf, L.S., Kuendig, R., Adam, F. (2015). Urban mining as a contribution to the resource strategy of the Canton of Zurich. Waste Management, Urban Mining 45, 10-21. https://doi. org/10.1016/j.wasman.2015.06.045

Singh, J., Ordoñez, I. (2015). Resource recovery from post-consumer waste: important lessons for the upcoming circular economy. Journal of Cleaner Production. https://doi.org/10.1016/j.jclepro.2015.12.020

Song, Q., Li, J. (2015). A review on human health consequences of metals exposure to e-waste in China. Environmental Pollution 196 450-461. https://doi.org/10.1016/j.envpol.2014.11.004

Song, Q., Wang, Z., Li, J. (2012). Residents' behaviors, attitudes, and willingness to pay for recycling e-waste in Macau. Journal of Environmental Management 106, 8-16. https://doi.org/10.1016/j. jenvman.2012.03.036

Stahel, W. (1977). The potential for substituting manpower for energy: Final report 30 July 1977 for the Commission of the European Communities. Battelle, Geneva Research Centre.

Step Initiative (2014). Solving the E-Waste Problem (Step).

Stewart, R., \& Niero, M. (2018). Circular economy in corporate sustainability strategies: A review of corporate sustainability reports in the fast-moving consumer goods sector. Business Strategy and the Environment. https://doi.org/10.1002/bse.2048

Strahilevitz, M., Loewenstein, G. (1998). The Effect of Ownership History on the Valuation of Objects. Journal of Consumer Research 25, 276-289.

Su, B., Heshmati, A., Geng, Y., Yu, X. (2013). A review of the circular economy in China: moving from rhetoric to implementation. Journal of Cleaner Production 42, 215-227. https://doi.org/10.1016/j. jclepro.2012.11.020

Swami, V., Chamorro-Premuzic, T., Snelgar, R., Furnham, A. (2011). Personality, individual differences, and demographic antecedents of self-reported household waste management behaviours. Journal of Environmental Psychology 31, 21-26. https://doi.org/10.1016/j. jenvp.2010.08.001

Thaler, R. (1980). Toward a Positive Theory of Consumer Choice. Journal of Economic Behavior and Organization 1, 39-60.

Thaler, R.H., Sunstein, C.R., Balz, J.P. (2008). Choice Architecture, in: The Behavioral Foundations of Public Policy. Eldar Shafir, pp. 428-439.
Thaler, R.H., Sustein, C.R. (2003). Libertarian Paternalism. The American Economic Review 93, 175-179.

The Economist (2016). The scientists who make apps addictive [WWW Document]. 1843. URL https://www.1843magazine.com/features/ the-scientists-who-make-apps-addictive (accessed 3.29.17).

Thi Thu Nguyen, Hong, Hung, R.-J., Lee, C.-H., Thi Thu Nguyen, Hang (2018). Determinants of Residents' E-Waste Recycling Behavioral Intention: A Case Study from Vietnam. Sustainability 11, 164. https://doi.org/10.3390/su11010164

Tonglet, M., Phillips, P.S., Bates, M.P. (2004). Determining the drivers for householder pro-environmental behaviour: Waste minimisation compared to recycling. Resources, Conservation and Recycling 42, 27-48. https://doi.org/10.1016/j.resconrec.2004.02.001

Tversky, A., Kahneman, D. (1991). Loss Aversion in Riskless Choice: A Reference-Dependent Model. The Quarterly Journal of Economics 106, 1039-1061. https://doi.org/10.2307/2937956

Tversky, A., Kahneman, D. (1982). Judgment under Uncertainty: Heuristics and Biases. Science 185, 1124-1131.

Vence, X., \& Pereira, Á. (2019). Eco-innovation and Circular Business Models as drivers for a circular economy. Contaduria y Administracion. https://doi.org/10.22201/fca.24488410e.2019.1806

Wallsten, B., Magnusson, D., Andersson, S., Krook, J. (2015). The economic conditions for urban infrastructure mining: Using GIS to prospect hibernating copper stocks. Resources, Conservation and Recycling 103, 85-97. https://doi.org/10.1016/j.resconrec.2015.07.025

Wan, C., Shen, G.Q., Yu, A. (2014). The role of perceived effectiveness of policy measures in predicting recycling behaviour in Hong Kong. Resources, Conservation and Recycling 83, 141-151. https://doi. org/10.1016/j.resconrec.2013.12.009

Wilkinson, A., Williams, I.D. (2019, October). Why do (W)EEE hoard? The effect of consumer behaviour on the release of (W)EEE from home entertainment products into the circular economy [Paper presentation], in: Proceedings of the Seventeenth International Waste Management and Landfill Symposium. The 17th International Waste Management and Landfill Symposium, S. Margherita di Pula, Cagliari, Sardinia, Italy (pp. 196-201).CISA.

Williams, I.D. (2016). 'Global Metal Reuse, and Formal and Informal Recycling from Electronic and Other High-Tech Wastes', Metal Sustainability (pp. 23-51). John Wiley \& Sons, Ltd. https://doi. org/10.1002/9781119009115.ch2

Williams, I.D., Gunton, H. (2007, April). Waste minimisation using behaviour change techniques: a case study for students. in: Waste Matters: Integrating Issues. Proceedings of 2nd BOKU Waste Conference, Vienna, Austria (pp. 303-314). Waste Conference Ltd.,

Wilson, G.T., Smalley, G., Suckling, J.R., Lilley, D., Lee, J., Mawle, R. (2017). The hibernating mobile phone: Dead storage as a barrier to efficient electronic waste recovery. Waste Management, Special Thematic Issue: Urban Mining and Circular Economy 60, 521-533. https://doi.org/10.1016/j.wasman.2016.12.023

WRAP. (2013). Increase your small WEEE collection rates I WRAP UK [WWW Document]. URL http://www.wrap.org.uk/content/increaseyour-small-weee-collection-rates (accessed 9.3.16).

Wright, M. (2015). How the circular economy is taking off in the US. The Guardian.

WTO. (2014). China - Measures Related to the Exportation of Rare Earths, Tungsten and Molybdenum (Dispute Settlement No. DS431). World Trade Organisation, Switzerland.

Zhang, K., Kleit, A.N. (2016). Mining rate optimization considering the stockpiling: A theoretical economics and real option model. Resources Policy 47, 87-94. https://doi.org/10.1016/j.resourpol.2016.01.005

Zhang, L., Qu, J., Sheng, H., Yang, J., Wu, H., Yuan, Z. (2019). Urban mining potentials of university: In-use and hibernating stocks of personal electronics and students' disposal behaviors. Resources, Conservation and Recycling 143, 210-217. https://doi. org/10.1016/j.resconrec.2019.01.007 